\title{
Peran Kepala Sekolah Sebagai Manager Dalam Menciptakan Sekolah Efektif di SMP An-Nur Bululawang Malang
}

\author{
Romadhon \\ Dosen FIP/PGSD Universitas Kanjuruhan Malang \\ E-mail: romadhon@unikama.ac.id
}

\begin{abstract}
Abstrak
Sekolah yang bermutu ditentukan oleh peran kepala sekolah. Peranan kepala sekolah sangat strategis dalam menciptakan sekolah yang efektif. Salah satu peran yang strategis adalah sebagai manager. Tujuan penelitian ini untuk mengetahui sejauh mana peran kepala sekolah sebagai manager dalam menciptakan sekolah yang efektif. Pendekatan dalam penelitian ini yaitu kualitatif deskriptif. Teknik pengumpulan data dilakukan dengan wawancara, observasi, dan dokumentasi. Subjek dalam penelitian ini adalah kepala sekolah, para wakil kepala sekolah (kaur), dan guru. Hasil penelitian menunjukkan bahwa kepala sekolah belum sepenuhnya menjalankan perannya sebagai manager sebagaimana dalam Permendiknas Nomor 13 Tahun 2007 terutama dalam hal pendayagunaan SDM, pengelolaan hubungan sekolah dengan masyarakat, pengelolaan unit layanan khusus, penerapan prinsip kewirausahaan, menciptakan budaya dan iklim kerja yang kondusif, pengelolaan sistem informasi sekolah, dan pelaksanaan pengawasan (supervisi).
\end{abstract}

Kata kunci: Peran kepala sekolah, manager, sekolah efektif

\begin{abstract}
Quality schools are determined by the role of the principal. The role of the principal is very strategic in creating effective schools. One strategic role is as a manager. The purpose of this study is to determine the extent of the role of the principal as a manager in creating an effective school. The approaches in research was qualitative descriptive. The techniques of collecting the data were interview, observation, and documentation. The subjects of this study were headmaster, vice-headmaster, chives, and the teachers. The result of this research shows that the roles of headmaster as manager in creating the effective school are, the headmaster has not fully do his roles as a manager yet as in Permendiknas No. 13, 2007, especially on the page of empowering the human resources, organizing the relationship between school and society, organizing the special unit, implementing the principle of entrepreneurship, creating cultures and good working atmosphere, organizing the school information system, and the implementation of controlling the school activities.
\end{abstract}

Keywords: Roles of headmaster, manager, effective school

\section{PENDAHULUAN}

Sekolah sebagai lembaga pendidikan

bertugas menyelenggarakan proses

pendidikan dan proses belajar mengajar

dalam usaha untuk mencerdaskan

kehidupan bangsa seperti dalam

pembukaan UUD 1945. Proses belajar disekolah tentu tidak terlepas dari keberdaan guru terutama kepala sekolah yang banyak menentukan keberhasilan sekolah. Kepala sekolah sebagai seseorang yang diberi tugas untuk memimpin sekolah, bertanggung jawab atas tercapainya visi, misi, dan tujuan sekolah. Kualitas 
kepemimpinan kepala sekolah memiliki signifikansi terhadap keberhasilan sekolah. Kepala sekolah harus memiliki kemampuan untuk memberdayakan seluruh Sumber Daya Manusia (SDM) yang ada untuk mencapai visi, misi dan tujuan sekolah (Hariandja dan Yovita, 2002).

Seorang pemimpin, dalam hal ini kepala sekolah dituntut memiliki kemampuan dalam mengelola organisasi/sekolah. Kemampuan tersebut menurut Wijoyo (2011) harus melekat dalam diri seorang pemimpin/kepala sekolah yang meliputi; 1) Kemampuan menjalankan kekuasaan dengan efektif, dan dengan cara tanggungjawab; 2) Kemampuan untuk memahami bahwa manusia mempunyai motivasi hidup, waktu, dan situasi yang berbeda; 3) Kemampuan untuk mengilhami; dan 4) Kemampuan untuk bertindak dengan cara mengembangkan iklim yang menguntungkan untuk menanggapi, dan memberikan motivasi.

Penelitian Usman (2009) sampai pada kesimpulan bahwa meski semua komponen manajemen bagus tetapi kepala sekolahnya kurang mumpuni terutama dalam manajemen, maka sekolah tidak efektif. Tidak ada sekolah yang unggul dipimpin oleh kepala sekolah yang tidak unggul. Sekolah yang hebat dipimpin oleh kepala sekolah yang hebat pula terutama dalam melaksanakan peran kepemimpinannya.

Kepemimpinan kepala sekolah sebaiknya menghindari terciptanya pola hubungan dengan guru yang hanya mengandalkan kekuasaan, dan sebaliknya perlu mengedepankan kerja sama fungsional. Kepala sekolah juga harus menghindarkan diri dari one man show, sebaliknya harus menekankan pada kerja sama kesejawatan, menghindari terciptanya suasana kerja yang menakutkan, dan sebaliknya perlu menciptakan keadaan yang bisa semua guru percaya diri dalam mengembangkan segala potensinya. Kepala sekolah juga dituntut untuk mengamalkan fungsi manajemen yaitu; planning, organizing, actuating and controlling, hal ini akan memberikan kontribusi bagi peningkatan kinerja guru. Fungsi manajemen ini akan berjalan secara sinergis dengan peran kepala sekolah sebagai educator, manager, administrator, supervisor, leader, inovator dan motivator (Mulyasa, 2012).

Menurut Murtiningrum (2014) dalam penelitiannya menunjukkan bahwa terdapat kontribusi yang signifikan perilaku kepemimpinan kepala sekolah, budaya organisasi, dan pemberian insentif terhadap kinerja guru baik secara mandiri ataupun secara simultan. Pada observasi awal menunjukkan bahwa kerja yang menjenuhkan, suasana lingkungan kerja 
yang inkondusif seperti teman yang tidak saling mendukung, kebijakan pimpinan yang kurang mendukung, siswa yang tingkah lakunya kurang disiplin, dan tertib inilah yang terjadi di beberapa sekolah termasuk lokasi penelitian ini. Disisi lain, ada yang menurun semangatnya dalam mengajar, merasa bosan, jenuh dengan pekerjaan dan tidak komitmen atas tanggujawabnya. Hal ini, menunjukkan bahwa iklim sekolah kurang berpihak pada kinerja guru yang menyebabkan sekolah tidak efektif.

Menurut Afandi (2014) dalam penelitinnya mengungkapkan bahwa peran kepemimpinan kepala sekolah yang efektif menggunakan teknik antara lain; sebagai mitra kerja, partisipator, supporter, memberikan mandat, membuat tempat kerja yang nyaman dan memberi contoh yang baik (uswatun hasanah) bagi para guru. Kepemimpinan kepala sekolah dituntut untuk melaksanakan tugas dengan penuh tanggungjawab, loyal, dan bekerja secara profesional sehingga mampu meningkatkan tanggungjawab guru dalam tugas, prestasi yang dicapai, pengembangan diri dan kemandirian dalam bertindak.

Sehubungan dengan kepemimpinan kepala sekolah, dalam 5 tahun terakhir SMP An-Nur Bululawang yang berada dibawah naungan Yayasan Pendidikan Pondok Pesantren (YP3) An-Nur telah banyak mengalami perkembangan seperti jumlah siswa setiap tahunnya mencapai sekitar 1000 siswa, pengadaan ruang kelas baru, berbagai macam kegiatan siswa dan rekrutmen guru dan karyawan setiap tahunnya. Dengan perubahan tersebut tentu mendorong kerja kepala sekolah lebih maksimal mengelola lembaga ini terutama dalam hal manajerial. Manajerial menjadi denyut nadi pengembangan sekolah yang akan beriringan dengan kualitas sekolah. Begitu juga dengan iklim sekolah yang diharapkan mendapat dukungan dari seluruh stakeholder yang ada demi mencapai visi, misi dan tujuan sekolah.

Berdasarkan uraian latar belakang, maka penelitian ini difokuskan pada peran kepemimpinan Kepala SMP An-Nur Bululawang sebagai manager dalam menciptakan sekolah yang efektif. Dengan tujuan penelitian untuk mengetahui sejauh mana peran kepala sekolah sebagai manager dalam menciptakan sekolah yang efektif

\section{METODE PENELITIAN}

Penelitian ini adalah kualitatif dengan jenis penelitian adalah penelitian lapangan (field research), dengan prosedur penelitian yang menggali data dari lapangan untuk kemudian dicermati, dianalisa dan disimpulkan. Penelitian kualitatif dianggap tepat karena sesuai dengan masalah yang dirumuskan peneliti 
sebelumnya. Penggunaan penelitian kualitatif ini juga bertujuan supaya data-data yang diperoleh lebih mendalam sesuai dengan makna dan fakta di lapangan. Penelitian dilakukan pada semester genap Bulan Januari sampai Mei 2018 dengan subjek utama dalam penelitian ini adalah Kepala Sekolah, satu orang Wakil Kepala Sekolah, empat orang Kepala Urusan (Kaur), dua orang guru tersertifikasi dan dua orang guru yang belum sertifikasi.

Teknik pengumpulan data yang sesuai dengan fokus dan tujuan penelitian kualitatif, dengan melakukan teknik yaitu wawancara, observasi, dan dokumentasi seperti terlihat pada tabel berikut :

Tabel. 2. Tiga Teknik Pengumpulan Data

\begin{tabular}{lcc}
\hline \multicolumn{1}{c}{ Uraian } & $\begin{array}{c}\text { Kod } \\
\text { e }\end{array}$ & $\begin{array}{c}\text { Keteranga } \\
\text { n }\end{array}$ \\
\hline Teknik & Huru & Observasi \\
Pengumpula & f O \\
n Data & & \\
\hline \multicolumn{3}{c}{ Huru } \\
f W & Wawancara \\
\hline & Huru & Dokumenta \\
& f D & si \\
\hline Data yang dihasilkan dari penelitian
\end{tabular}
ini adalah berupa kata-kata atau kalimat deskriptif oleh karena itu akan dianalisis dengan analisis isi. Langkah yang dilakukan pada analisis isi melalui 4 komponen yang saling berkaitan yakni: mengoleksi data, mereduksi data, menyajikan data (display) serta menarik kesimpulan (verifikasi) ditunjukkan pada gambar 1 berikut.

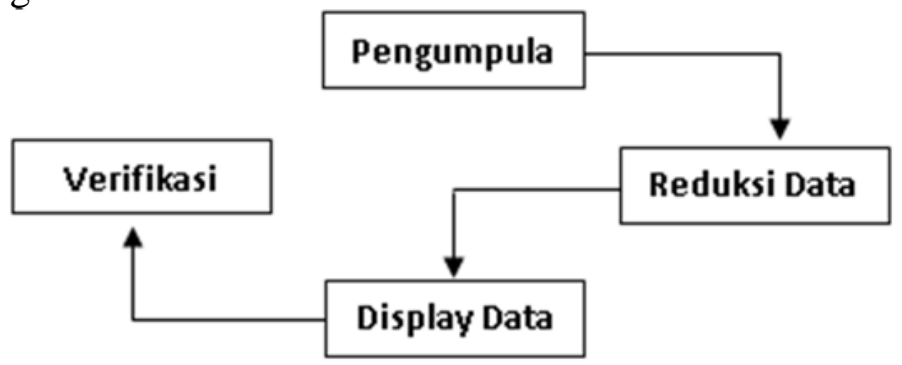

Gambar 1. Komponen dalam analisis data (Sugiyono, 2010)

\section{HASIL DAN PEMBAHASAN}

Dari hasil penelitian diatas, peran kepala SMP An-Nur sebagai manager dengan melihat indikator yang tercantum dalam Peraturan Menteri Pendidikan Nasional Nomor 13 Tahun 2007 belum dijalankan sepenuhnya sebagai tolok ukur keberhasilan dalam menjalankan kepemimpinan kepala sekolah. Adapun yang belum dijalankan oleh kepala sekolah terlihat pada aspek organizing dan controlling, misalnya; pendayagunaan SDM, pengembangan organisasi, pengelolaan hubungan sekolah dengan masyarakat, pengelolaan unit layanan khusus, penerapan prinsip kewirausahaan, menciptakan budaya dan iklim kerja yang kondusif, pengelolaan sistem informasi sekolah, dan pelaksanaan pengawasan (supervisi). Sebagaimana dalam fatwa pengasuh "sekolah membantu pondok pesantren”, sehingga dalam pelaksanaannya kepala sekolah belum melakukan open management yang idealnya harus dilakukan oleh sekolah sebesar seperti SMP An-Nur ini. 
Menurut Nurkholis (2005), peran kepala sekolah sebagai manager harus mampu memerankan fungsi manajerial yakni planning, organizing, actuating, dan controlling. Hasil penelitian di SMP AnNur menunjukkan kepala sekolah menjalankan fungsi manajerial pada aspek planning dan actuating saja. Hal ini terlihat pada perencanaan sekolah, pengelolaan kesiswaan, pengelolaan sarana dan prasarana, pengembangan kurikulum, pengelolaan keuangan sekolah, ketatausahaan sekolah, dan pemanfaatan kemajuan teknologi informasi. Padahal tuntutan kepala sekolah ke depan tidak hanya mampu merencanakan, kepala sekolah dituntut untuk mampu melakukan controlling pada semua aspek yang telah direncanakan agar fungsi manajerial bisa digunakan bahan evaluasi dalam pengambil kebijakan termasuk kebijakan strategis dalam menciptakan sekolah efektif.

Senada dengan penelitian ini, Jamali dan Parsojo (2013) menyimpulkan bahwa jika kompetensi managerial kepala sekolah, lingkungan sekolah, dan motivasi berprestasi guru ditingkatkan kualitasnya, maka akan berkontribusi positif terhadap peningkatan prestasi siswa. Hal inilah sekolah bisa dikatakan efektif karena mampu menghasilkan prestasi yang cemerlang, bukan karena besar kecilnya jumlah siswa atau sekolah, melainkan manajemen sekolah, pendayagunaan SDM dan motivasi berprestasi guru yang terus dikembangkan.

Lemahnya dalam kepengawasan (supervisi) juga membuat peran kepala sekolah sebagai manager belum dilakukan dalam rangka meningkatkan kualitas sumber daya manusianya. Kepala sekolah menyadari bahwa peningkatan SDM perlu dilakukan agar seimbang antara kuantitas dengan kualitas. Seperti kutipan dalam wawancara;

"Menurut saya, selama saya ngajar disini
(5 tahun) tidak pernah mendapatkan
supervisi dari kepala sekolah. Namun,
memimpin secara legal formal, saya
yakin semuanya terpimpin".
(W.G4.1/4/2018)

Dalam menciptakan budaya dan iklim kerja yang kondusif menjadi harapan tersendiri kepala sekolah. Kepala sekolah terus berupaya menciptakan hal itu. Namun, masih saja ditemukan budaya dan iklim kerja yang inkondusif, seperti guyonan 'gojlokin' yang berlebihan di ruang guru, guru hanya sekedar datang untuk mengajar, terjadi kelas yang kosong dan kedisiplinan siswa yang juga masih kurang. Kepala sekolah terus mengingatkan baik saat rapat dewan guru maupun rapat pimpinan (rapim) agar setiap guru terus terlibat aktif dalam menciptakan iklim yang kondusif. Namun, pada kenyataan hanya sedikit yang mau melibatkan diri dalam menciptakan iklim yang kondusif. Seperti dalam kutipan wawancara berikut;

”Hal itu tergantung masing-masing 
guru, setiap bulan guru selalu diberikan arahan oleh kepala sekolah. Kepala sekolah juga menerima masukan/saran terkait dengan guru yang kurang disiplin. Sementara itu setiap pagi ada yang bertugas (guru piket) memantau kedispilinan guru, namun hasilnya untuk kepentingan internal. Karena kami tetap menjaga ranah kekeluargaan demi kebaikan kita bersama”. (W.KSP.3/4/2018)

Dalam penelitian Taswilin (2014) yang menyatakan bahwa budaya kerja guru berpengaruh positif dan signifikan terhadap prestasi siswa. Budaya yang dimaksud adalah kebiasaan guru dalam melengkapi administrasi guru, proses pembelajaran oleh guru, dan guru dapat mengevaluasi pembelajaran secara keseluruhan. Untuk itu, guru menjadi ujung tombak dalam pembelajaran baik dalam kelas maupun lingkungan sekolah. Kepala sekolah seyogyanya melakukan supervisi pembelajaran sebagai langkah menciptakan budaya dan iklim yang kondusif.

Berdasarkan hasil dan pembahasan diatas, peran kepala sekolah sebagai manager belum berjalan efektif, hal ini tentu tidak berdiri sendiri. Menurut Burhanuddin (2004) ada beberapa faktor yang mendukung sekaligus menghambat efektifitas kepemimpinan kepala sekolah antara lain; 1). Kepribadian; 2). Pemahaman dan penguasaan tujuan pendidikan (purposes); 3). Pengetahuan; dan 4). Keterampilan profesional.

Selain itu, kepala sekolah dituntut juga mengembangkan keterampilan profesionalnya. Keterampilan profesioanal yang dimaksudkan adalah kemampuan menjalankan peran kepala sekolah secara umum. Mulyasa (2012) menyebutkan peran kepala sekolah anatara lain; sebagai educator, Manager, administrator, supervisor, leader, inovator dan motivator. Mengasah keterampilan profesional menjadi tuntutan kewajiban dalam meningkatkan kualitas kepala sekolah.

Dengan demikian posisi kepala sekolah, guru dan seluruh stakeholder menjadi kunci keberhasilan sekolah dimasa yang akan datang. Kepala sekolah harus sinergi dengan semua stakeholders, lebihlebih pada pimpinan SMP An-Nur Bululawang harus bisa dijadikan uswah dalam setiap perkataan, perbuatan dan profesionalitas dalam menjalankan tugas dan fungsinya.

\section{SIMPULAN}

Berdasarkan hasil dan pembahasan tentang peran kepala sekolah sebagai manager dalam menciptakan sekolah efektif. Peran kepala sekolah sebagai manager belum sepenuhnya dijalankan sebagimana dalam Peraturan Menteri Pendidikan Nasional Nomor 13 Tahun 2007 dengan tetap memperhatikan konsep manajemen yakni Planning, Organizing, Actuating, Controlling, sebagai upaya dalam menjalankan perannya untuk 
menciptakan sekolah yang efektif, terutama dalam hal penyusunan perencanaan sekolah, pengembangan organisasi sekolah, pendayagunaan SDM, pengelolaan hubungan sekolah dengan masyarakat, pengelolaan kesiswaan, pengelolaan ketatausahaan, pengelolaan unit layanan khusus, penerapan prinsip kewirausahaan, menciptakan budaya dan iklim kerja yang kondusif, pengelolaan sistem informasi sekolah, dan pelaksanaan pengawasan terhadap kegiatan sekolah. Peran kepala sekolah yang didominasi oleh yayasan akan berdampak pada ketidakmaksimalan peran kepala sekolah terutama sebagai manager. Sebaiknya yayasan menjalankan perannya sebagai monitoring dan evaluasi (monev) terhadap kinerja kepala sekolah dalam rangka memberikan inovasi dalam setiap pengembangan sekolah kedepan.

\section{DAFTAR PUSTAKA}

Afandi (2014). Peran Kepemimpinan Kepala Sekolah SMP Muhammadiyah 2 Kota Tarakan. Tesis. Malang: Program Pascasarjana Universitas Muhammadiyah Malang.

Bush and Coleman (2010). Manajemen Strategi Kepemimpinan Pendidikan. Terj. Fahrurrozi, Cet. Ke-3. Jogjakarta: IRCiSoD

Fachrudi, Indra (2006). Bagaimana Memimpin Sekolah yang Efektif. Malang: Ghalia Indonesia Ciawi Bogor

Hariandja, Efendi \& Yovita H. (2002). Manajemen Sumber Daya Manusia:
Pengadaan, Pengembangan, Pengkompensasian dan Peningkatan Produktivitas Pegawai. Bandung: Grasindo Widiasrana Indonesia

Heclinger, F. (1981). Effective School, Effective Principal. Resto, VA: NASSP

Jamali Ari \& Prasojo LD (2013). Pengaruh Kompetensi Managerial Kepala Sekolah Lingkungan, Motivasi Guru terhadap Prestasi Siswa SMA Muhammadiyah Kota Yogyakarta. Jurnal Akuntabilitas Manajemen Pendidikan Pascasarjana Universitas Negeri Yogyakarta (Volume 1, Nomor 1 Tahun 2013)

Moeleong (2013). Metodologi Penelitian Kualitatif. Bandung: Remaja Rosdakarya

Mulyasa, E. (2007). Menjadi Kepala Sekolah Profesional. Bandung: Remaja Rosdakarya.

(2012). Manajemen dan Kepemimpinan Kepala Sekolah. Jakarta: Bumi Aksara

Murtiningrum, Hasti (2014). Kontribusi Perilaku Kepemimpinan Kepala Sekolah, Budaya Organisasi, Dan Pemberian Insentif Terhadap Kinerja Guru (Studi Persepsi Guru SMP Negeri Se-Kecamatan Kubu). $e$ Journal Program Pascasarjana Universitas Pendidikan Ganesha Singaraja Indonesia Program Studi Administrasi Pendidikan (Volume 5 Tahun 2014)

Nurkholis (2005). Manajemen Berbasis Sekolah, Teori, Model, dan Aplikasi. Jakarta: PT. Grasindo

Rozhana, K,M \& Sari, N,K. 2018. Pelaksanaan Pendidikan Karakter dalam Proses Pembelajaran untuk Menumbuhkan Sikap Nasionalisme. Prosiding Seminar Nasional 
Pengembangan Profesionalisme Dosen dan Guru Indonesia, Volume 2 (Online)

(https://semnas.unikama.ac.id/fip/un duhan/2018/47851298.pdf), di akses 2 mei 2019.

Sugiyono (2010). Metode Penelitian Pendidikan Pendekatan Kuantitatif, Kualitatif, dan R\&D. Bandung: Alfabeta

Taswilin, Wiwin (2014). Pengaruh Budaya Kerja Guru dan Manajemen Sarana Prasarana terhadap Prestasi Siswa. Jurnal Ilmiah Mahasiswa Pascasarjana Administrasi Pendidikan (Volume 2, Nomor 4 Juli 2014)
Townsend, Tony (1994). Effective Schooling for The Community: Coreplus Education. Routledge. London and New York.

Usman, Husaini (2009). Manajemen, Teori, Praktik, dan Riset Pendidikan. Jakarta: Bumi Aksara

Wijoyo, Bintoro (2011). Kepemimpinan Kepala Sekolah Dalam Peningkatan Motivasi Kerja Guru Di SMAN 1 Gangga Lombok Utara. Tesis. Program Pascasarjana Universitas Muhammadiyah Malang

Peraturan Menteri Pendidikan Nasional Nomor 13 Tahun 2007 Tentang Standar Kompetensi Kepala Sekolah/Madrasah. 